\title{
COVID-19 PANDEMIC LOCKDOWN RESPONSES FROM AN EMOTIONAL PERSPECTIVE: FAMILY FUNCTION AS A DIFFERENTIAL PATTERN AMONG OLDER ADULTS
}

\author{
Javier López, Gema Pérez-Rojo, Cristina Noriega, Cristina Velasco, \\ Isabel Carretero, Patricia López-Frutos and Leyre Galarraga \\ San Pablo-CEU University (Spain)
}

\begin{abstract}
Family can be an essential resource at times of loss or vital crisis. Loneliness and isolation in older adults might have serious negative consequences for their mental health. For this reason, this research aims to analyze the role of family function in the anxiety and depression experienced by older adults during the pandemic caused by COVID-19. Participants were 882 Spanish communitydwelling adults over 60 years of age. Sociodemographic characteristics, characteristics related to the coronavirus, self-perceived health, family function, avoidance, depression and anxiety were analyzed. Data suggest a buffering effect of family function on anxiety and depression during the pandemic. Furthermore, being unmarried or a female, greater fear of COVID-19, worse self-perceived health, greater avoidance, and worse family function were associated with higher levels of anxiety. Likewise, greater fear of COVID-19, poorer self-perceived health, greater avoidance, and poorer family function, were associated with greater depression. These results point out that family dysfunction is a predisposing factor for the development of the emotional problems of anxiety and depression in older people in potentially stressful and loss situations.

KEY WORDS: COVID-19, coronavirus, emotional problems, family function.
\end{abstract}

\section{Resumen}

La familia puede ser un recurso fundamental en momentos de pérdidas y crisis vitales. La soledad y el aislamiento en personas mayores provocan consecuencias negativas para su salud mental. La presente investigación analiza el rol de la función familiar en la ansiedad y depresión experimentadas por personas mayores durante la pandemia ocasionada por el COVID-19. Participaron 882 adultos mayores de 60 años evaluándose características sociodemográficas y del coronavirus, salud, función familiar, evitación, depresión y ansiedad. Los datos sugieren un factor amortiguador de la función familiar sobre la ansiedad y depresión durante la pandemia. Además, no estar casado, ser mujer, mayor miedo al COVID-19, una peor salud autopercibida, mayor evitación y una peor función familiar se asociaba con mayores niveles de ansiedad. Mientras que

The authors gratefully acknowledge to all the people who contributed to this study. This work was supported by San Pablo-CEU University (CEU-Santander, grant number MCOV20V3).

Correspondence: Javier López, School of Medicine, San Pablo-CEU University, Campus of Montepríncipe, 28925 Alcorcón, Madrid (Spain). E-mail: jlopezm@ceu.es 
mayor miedo al COVID-19, una peor salud autopercibida, mayor evitación y una peor función familiar se relacionaban con mayor depresión. Los resultados permiten señalar que la disfunción familiar es un factor predisponente para el desarrollo de problemas emocionales de ansiedad y depresión en personas mayores en situaciones potencialmente estresantes y de pérdida.

PALABRAS CLAVE: COVID-19, coronavirus, problemas emocionales, función familiar.

\section{Introduction}

The COVID-19 pandemic has spread globally, and although the virus can infect anyone, older adults are a particularly vulnerable population, with a higher risk of becoming seriously ill (Verity et al., 2020).

As in the case of other recent outbreaks, including those of Zika, Ebola and SARS, drastic preventive measures, such as confinement, have been taken with the aim to halt its spread. However, it had to be COVID-19 expansion worldwide which has made people became aware of the real impact of a pandemic in the 21 st century, increasing anxiety and distress in developed and developing societies alike. Home confinement has a suitable purpose and its benefits have been demonstrated, but it can be an additional source of stress, generating feelings of loneliness, anxiety and depressive symptomatology (Brooks et al., 2020; Huremović, 2019).

The COVID-19 outbreak entails losses of diverse nature and it is a potentially traumatic event. Research highlights its negative consequences to the physical, psychological, and social levels. People's everyday life have been affected by the COVID-19 crisis by issues such as lack of resources to cover basic needs, lack of medical supplies, loss of employment, and also privation of emotional and social support (Brooks et al., 2020; Ibáñez-Vizoso et al., 2020). All this together has led to higher levels of stress, anxiety and depression in the adult population (Wang et al., 2020).

Regarding older people, they have expressed higher levels of loneliness and depression than prior to the restriction of movements (Krendl and Perry, 2020; Meng et al., 2020), have experienced significant levels of anxiety (Bergman et al., 2020; Meng et al., 2020), and longitudinal studies indicate that emotional distress has increased when compared to previous measures to the pandemic (Pierce et al., 2020).

In addition, the situation generated by COVID-19 has reinforced the presence of ageism, by associating, for example, disease with aging, considering elderly people as a group in which all their members are vulnerable and fragile, characterized by loss, and must be overprotected (Ayalon, 2020). However, despite the fact that most of the research on the elderly and the virus has focused on a negative (ageist) view of aging, some studies have highlighted the heterogeneity of this population under an adverse and potentially stressful event, such as the confinement (López et al., 2020).

It is well known how family can be an essential resource for all people, including the elderly, in times of loss, crisis or vital trauma (Caycho-Rodríguez et 
al., 2018; MacLeod et al., 2016) or, on the contrary, be a factor hindering the coping with such situations, or even a source of distress (Yon et al., 2017). Since family can be a source of support or of conflict, it is of great interest to evaluate family dynamics in older people.

Family function is the way in which a family works as a unit, it denotes the family's ability to cope and adapt to different situations (Smilkstein, 1980). Knowing family functioning is important to identify strengths that can serve as buffers to cope with stressors. According to Smilkstein (1978, 1980), the family's ability to adapt or cope with crisis depends on its resources (adaptation, association, growth, affection, and resolution). The impact of a stressful life event on a family will serve as a starting point in the study of family function. A nurturing family maintains balance by using its intrinsic resources to meet the daily needs of its members. However, stressful life events create an imbalance that requires a coping response from all family members, are in those moments when family resources are tested.

A family is considered functional when the definition of tasks or functions are clear and are accepted by all members when it comes to help solving problems using their own resources. In the opposite situation, the dysfunctional family is one in which there is a lack of respect, an overlap in the family hierarchy, problems in communication among its members, and inability for (re) organization of the family system, if necessary, for the articulation of resources for problem solving (Vera et al., 2014).

A review on family functioning of the elderly in Latin-American countries highlighted the presence of functional families in most cases, the percentages found by the different studies ranging between 60 and $87.1 \%$ for normal family function (Vera et al., 2014). According to a study carried out by Wang and Zhao (2012), family functioning was found to be a protective factor against vulnerability to stressful life events in older people. However, previous research indicates that family functioning may be conditioned by variables such as physical health (Andrade et al., 2020; Vera et al., 2014) or the acceptance or avoidance of one's own emotions (Fobair \& Zabora, 1995).

However, there are no studies in our context that analyze the association between family functioning and the emotional distress of older people in stressful situations and, as far as we know, there is a lack of studies that analyze the role of family functioning in a pandemic situation like the current one.

Loneliness and isolation have been related to different variables in older people, including depression and anxiety (Sutin et al., 2018). So it is to be expected that under the current situation that symptomatology, or their clinical diagnosis, will increase. Besides a great comorbidity has been found between the two (Braam et al., 2014; Wolitzky-Taylor et al., 2010).

Lazarus and Folkman (1984) developed a particularly useful and widely used stress process model. From its perspective, primary stressors, such as direct and indirect problems associated with COVID-19 (e.g., having symptoms, being hospitalized, hospitalization, or the death of a loved one), create the conditions under which emotional distress may occur, but the degree to which older adults experience distress or well-being will depend on their assessment of the event and 
the resources they may count with, to cope with stressor. In the present study, family functioning was considered a key resource. Taking into account this theoretical framework, that is, following this stress model, the current study aimed to investigate the role of family function during the COVID-19 lockdown in anxiety and depression experienced by people over 60 years of age.

\section{Method}

\section{Participants}

The sample consisted of 882 non-institutionalized Spaniard adults over 60 years of age (69.2\% from 60 to 70 and $30.8 \%$ from 71 to 85 years) who answered a survey three weeks after mobility restrictions were set in our country. Which in the case of older people required for them to stay at home permanently, and only to get out for special reasons (to buy groceries or medicines).

Most of the participants were women (62\%), lived with their spouse or partner $(63 \%)$, and reported perceived good $(43.70 \%)$ or normal health $(33.90 \%)$. A $88.4 \%$, had a highly functional family, $10.2 \%$ reported having a mild dysfunctional family and only $1.4 \%$ had a severe dysfunctional family.

In addition, 76 participants had COVID-19 symptoms; 9 had been hospitalized, 169 had a close family member or friend who had been hospitalized, and 93 reported the loss of a loved one to the virus. There were no significant differences in any of the effects of COVID-19 on them or on relatives and loved ones among the different types of families.

Among the participants there were 108 possible cases of anxiety and 57 of depression, as well as 58 possible anxiety disorders and 25 of depression. Table 1 shows how the older adults' characteristics are distributed across the different types of families.

\section{Instruments}

a) Family APGAR (Smilkstein, 1978). The Family APGAR is a brief five-item assessment tool used for a rapid assessment of 5 dimensions of family function: adaptation, association, growth, affect, and resolution. Participants evaluate each of the 5 dimensions based on the extent to which the person agrees with it. The scale presents three response alternatives: 0 points (almost never), 1 point (sometimes) and 2 points (almost always). The higher the score, the greater the indication of a functional family system. From 7 to 10 points implies a functional family (FF), from 4 to 6 points mild family dysfunction (MFD), from 0 to 3 points severe family dysfunction (SFD). Internal consistency reliability was reported as .84 (Cronbach's alpha) in the validation study of the Spanish version of the scale (Bellón et al., 1996). Cronbach's alpha reliability for the test proved to be satisfactory and amounted to .779 in the current sample. 


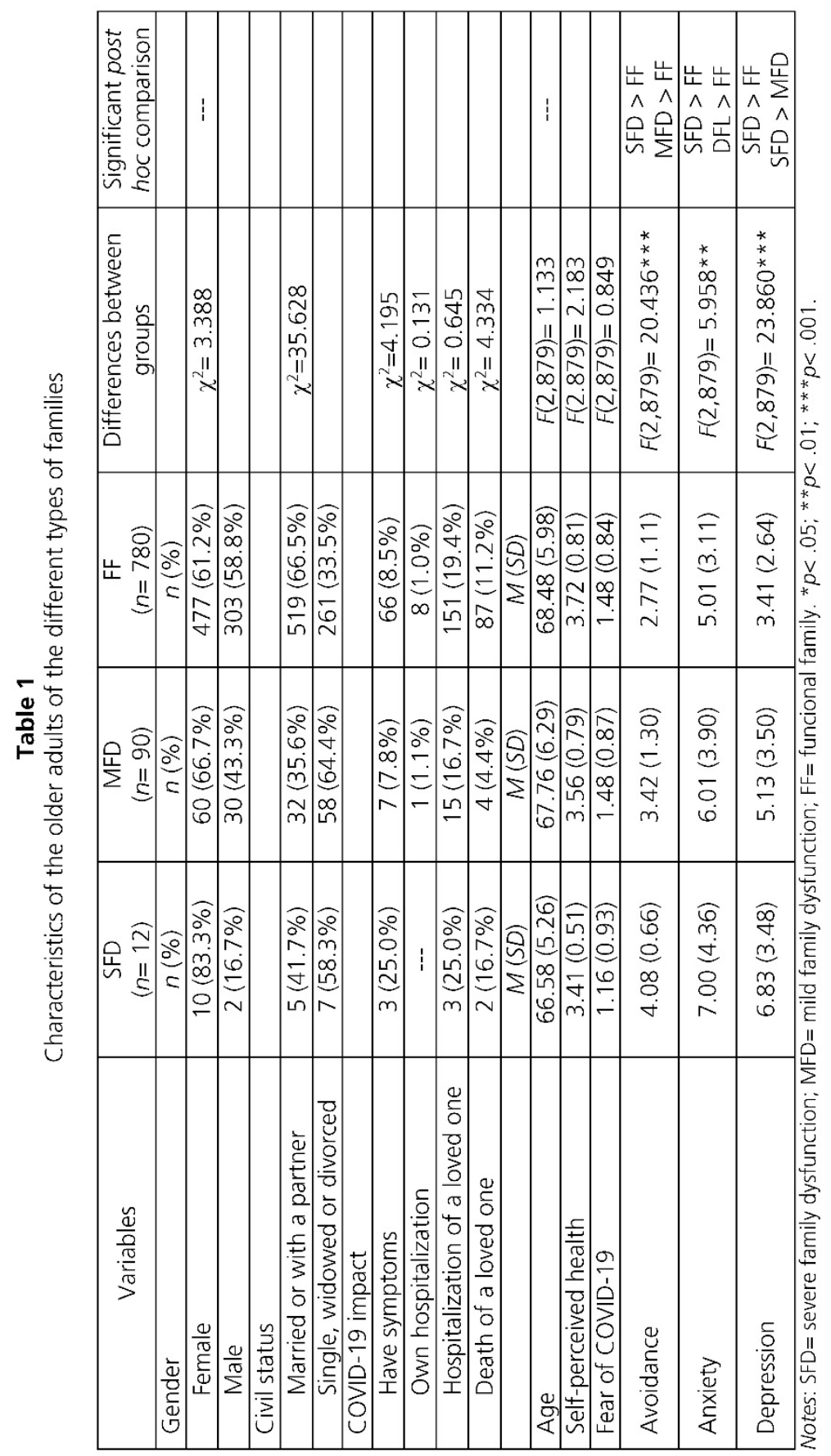


b) Acceptance and Action Questionnaire-II (AAQ-II; Bond et al., 2011). The AAQII is a 7-item instrument that was used to measure experiential avoidance. The participants evaluated the degree to which a series of thoughts and feelings described them, with a score ranging from 1 (very inadequate to describe myself) to 6 (very adequate to describe myself). Internal consistency reliability was ranged from .75 to .93 (Cronbach's alpha) in the validation study of the Spanish version of the scale (Ruiz et al., 2013). The instrument showed good reliability in our sample (Cronbach's $\alpha=.891)$.

c) Hospital Anxiety and Depression Scale (HAD; Zigmond \& Snaith, 1983). The HAD is a Likert scale composed of 14 items to which the patients respond through a 4-point scale (from 0 to 3 ) on the symptoms experienced in the last week. HAD excludes somatic symptoms of emotional distress (e.g., appetite problems, insomnia) that could be caused by factors associated with aging rather than expressions of emotional distress. It is made up of two scales: HAD-A for anxiety (7 items) and HAD-D for depression (7 items). The two scales have three cut-off points: absence of anxiety or depression problems (score between 0-7), probability of a problem (score between 8-10), possible anxiety or depression disorders (score equal to or greater than 11). HAD was designed to detect the presence of anxiety and depression in a setting, the hospital, in which certain behaviors such as weight loss, lack of appetite or sleep problems can be due to physical illness. In the case of older people, there is a risk of interpreting physical symptoms with anxiety and depression problems. Therefore, the choice of the HAD seemed appropriate to evaluate the sample of this study. In a review of 747 studies in which the HAD is used (Bjelland et al., 2002), it is found that although the scale is aimed at evaluating hospitalized patients, its adaptation to the sample of this study does not seem excessively complicated, nor problematic. Despite the word hospital that appears in its name, the HAD-A can also be used in community work. Internal consistency reliability was ranged from .74 to .86 for HAD-A and it was ranged from .71 to .87 for HAD-D (Cronbach's alpha) in a review study of the Spanish version of the scale (Terol-Cantero et al., 2015). In the present study, the HAD demonstrated good internal consistency with a Cronbach's alpha of .825 for HAD-A and .739 for HAD-D.

\section{Procedure}

An online survey was conducted (WhatsApp, Linkedln and Twitter). After obtaining informed consent, information was collected on the sociodemographic characteristics of the elderly, characteristics related to COVID-19 (having symptoms, being hospitalized, as well as hospitalization or death of a loved one), fear of COVID-19 (perception of fear from 1-Nothing to 5-Extremely) and selfperceived health (perception that the person has about the own general state of health, differentiating, as in the National Health Survey, five levels: Very bad, Bad, Fair, Good and Very good).

The study had the approval of the ethics committee of the San Pablo CEU University (Spain) (reference 436/20/26). 


\section{Data analysis}

Chi-square tests and ANOVAs of independent measures were used to verify the homogeneity of the different groups of family function. For post-hoc analyzes, the DMS test was used when the equality of variances was met and Games-Howell when it was not.

Stepwise multiple regression was used to analyze the association between anxiety and depression in the elderly (dependent variables), and the different variables that could influence them. The independent variables analyzed were sociodemographic (age, sex and being married or living with a partner), variables related to the coronavirus (having symptoms, being hospitalized, as well as hospitalization or death of a loved one), fear of COVID- 19, self-perceived health, avoidance and family function.

\section{Results}

As expected, differences were found between the three groups of families in anxiety $(F[2,879]=5.958, p<.01)$ and depression $(F[2,879]=23.860, p<.001)$. Post hoc analyzes revealed that the anxiety scores of the FF group were significantly lower than those of the SFD group (DMS $=-1.995, p<.05)$ and the MFD group (DMS $=-1.006, p<.01)$. The same pattern was observed in the case of depression: the DFG group scores were significantly higher than the FF group (DMS $=3.417$, $p<.001)$ and the MFD group (DMS=1.717, $p<.001)$. In addition, the MFD group showed lower levels of depression than the SFD group (DMS $=-1.700, p<.05$ )

No significant group differences emerged in the assessment of self-perceived health or variables related to COVID stress. However, the different groups of families showed differences in avoidance $(F[12,879]=25.451, p<.001)$, but did not experience differences in self-perceived health $(F[2,879]=2.183, p=.113)$ or in fear of COVID-19 $(F[2,879]=0.849, p=.428)$. Specifically, the elderly with families with FF experienced less avoidance than those of MFD (Games-Howell= $7.510, p<.01$ ) or those of SFD (Games-Howell $=-4.505, p<.001$ ).

Regression analyzes showed that family functioning explained both, level of anxiety and level of depression. As shown in Table 2, being single, widowed or without a partner, being a woman, greater fear of COVID-19, poorer selfperceived health, greater avoidance, and poorer family function were associated with greater anxiety in the elderly. These five factors explain $40 \%$ of the anxiety variance. On the other hand, as shown in Table 3, greater fear of COVID-19, poorer self-perceived health, greater avoidance, and poorer family function are associated with greater depression in the elderly. These four factors explain 35\% of the depression variance. 
Table 2

Stepwise multiple regression of anxiety

\begin{tabular}{|l|c|c|c|}
\hline \multicolumn{1}{|c|}{ Model } & $B$ & $\begin{array}{c}\text { Adjusted } \\
R^{2}\end{array}$ & $F$ \\
\hline Avoidance & 0.191 & .250 & $294.213^{* * *}$ \\
\hline Fear of COVID-19 & 1.273 & .376 & $266.895^{* * *}$ \\
\hline Self-perceived health & -0.530 & .389 & $188.210^{* * *}$ \\
\hline Sex (1= female, 2= male) & -0.673 & .396 & $145.320 * * *$ \\
\hline Civil status (1= married, 2= single/widowed/divorced) & 0.509 & .399 & $117.929 * * *$ \\
\hline Family function & -0.098 & .401 & 99.253 \\
\hline
\end{tabular}

Nota: ${ }^{* \star *} p<0,001$.

Table 3

Stepwise multiple regression of depression

\begin{tabular}{|l|c|c|c|}
\hline \multicolumn{1}{|c|}{ Modelo } & B & Adjusted $R^{2}$ & $F$ \\
\hline Avoidance & 0.170 & .270 & $326.460 * * *$ \\
\hline Fear of COVID-19 & 0.598 & .305 & $194.092 * * *$ \\
\hline Self-perceived health & -0.584 & .331 & $146.374 * * *$ \\
\hline Family function & -0.240 & .353 & $121.001 * * *$ \\
\hline
\end{tabular}

Nota: ${ }^{* *} p<0,001$.

\section{Discussion}

Family functioning is an essential factor in the preservation of health, or for the onset of disease among its members. If the family fulfills or ceases to fulfill its functions effectively, one can speak of functional or dysfunctional, family functionality deals with the ability of the family group to face and overcome the crises it is going through. The objective of this study was to assess the role that family function plays in the anxiety and depression experienced by people over 60 years of age during the COVID-19 crisis.

The results of the study point out how good family functioning is associated with less emotional distress (anxiety and depression). Also, being married and being male are associated with less anxiety. Finally, lower fear of the coronavirus, greater acceptance, and a better perception of own's health are associated with lower levels of anxiety and depression.

This study highlights the buffering effect that family function has on the anxiety and depression derived from the current COVID-19 pandemic. Previous research has pointed up a significant incidence of anxiety and depressive pathology in older people (Meng et al., 2020; Wolitzky-Taylor et al., 2010), this is likely to be a widespread phenomenon in countries severely affected by the 
coronavirus pandemic, since loneliness and isolation are related to both. In fact, there is preliminary evidence in this regard in China, the country where the pandemic originated, and where symptoms of moderate-severe intensity of anxiety $(28.8 \%)$ and depression (16.5\%) had already increased in the initial stage of the outbreak (Wang et al., 2020). The imposed home confinement implies a forced separation from family and friends which, along with other factors, causes an increase in uncertainty, as well as a feeling of loss of control. Although the response of most people to a stressor with the characteristics of the COVID-19 are adaptive, among the general principles for intervention with patients and staff is the avoidance of interpersonal isolation (Ibáñez-Vizoso et al., 2020). Furthermore, research has suggested that some aspects of family function (perceived criticism, hostility, etc.) play a role in most anxiety disorders. Similarly, negative interpersonal interactions are linked to the maintenance of depression and anxiety (Huppert, 2009; Itandehui et al., 2009). Specifically, a recent study found a negative relationship between depression and family functioning in older people (Lu et al., 2017). In line with previous research, the present study found that adequate family function contributes to the maintenance of low levels of anxiety and depression in the elderly within our sociocultural context.

In addition, being single, widowed or without a partner is associated with higher levels of distress. Good family functioning and being married or living with a partner are related to the absence of anxiety because it is associated with having ties with others (social contacts and social support) (Wolitzky-Taylor et al., 2010).

The ease of transmission of COVID-19 and the increased probability of mortality in the elder (Verity et al., 2019) have the potential to affect anxiety and emotional state by generating feelings of fear (worry by the quarantine, by being infected, by causing infections, by the potentially fatal consequences of the infection) (Ibáñez-Vizoso et al., 2020; Wang et al., 2020). For some older people, stressful events, such as confinement, can generate feelings of fear and decrease their ability to cope with daily challenges. The impact of fear is most evident when it is associated with a lack of perception of control. Thus, the lack of certainty about a possible negative outcome may lead to anxiety, and the feeling of not having control on the events (impotence) lead to depression (Huppert, 2009). In addition, the elderly show greater concerns and fears for health-related issues when compared to young adults (Wolitzky-Taylor et al., 2010). Therefore, it seems congruent that in the current study the fear to the coronavirus is associated with higher levels of depression and anxiety.

Anxiety and depression are characterized by affective, cognitive, and behavioral responses, that include not only early inhibition of behavior, increased negative affect, tendency to interpret ambiguous scenarios negatively and impairment in many areas of functioning, but also by avoidance (Huppert, 2009). Older people using acceptance as a way of coping reported greater well-being, while suppression, an emotional regulation strategy, was a negative predictor of well-being (Wolitzky-Taylor et al., 2010). Therefore, it is not surprising that greater 
avoidance (that is, the willingness to avoid experiencing unwanted thoughts, emotions, or bodily sensations) was associated in our study with higher levels of anxiety and depression. One of the risk factors associated with a higher probability of having an anxiety disorder at an advanced age is the subjective perception of a poor health, in coherence with this, we found that subjective poorer health was related with higher levels of both, anxiety and depression. Finally, being a woman was associated in our study with greater anxiety. These differences between men and women were also found in other studies that analyzed the implication of sex on mental health during the situation generated by the COVID-19 (Ibáñez-Vizoso et al., 2020). However, in our study we did not find differences between men and women regarding to depression levels.

Some limitations must be considered when interpreting the results of this study. First, the results come from people over 60 who have been contacted through websites and therefore may not be extrapolated to older people who are not in contact with such sites. An online survey, composed of various self-reports and ad hoc questions, was used due to the exceptional situation of confinement, which have prevented filling the data under the supervision of a health professional. However, the validity and reliability of surveys using the Internet have been shown to be comparable to telephone surveys, and even better (Chang \& Krosnick, 2009). The online procedure could also have resulted in the explained variance being only $40 \%$ and $35 \%$ for anxiety and depression respectively. However, these values are similar to, and even better than other studies on COVID-19 and the elderly (Bergman et al., 2020). Second, since it is a crosssectional study, no causal inferences can be made in the found relationships. Longitudinal studies would be required to inquire on the factors, that along with family functioning, contribute to the anxiety and depression generated by the confinement. Third, these findings are limited to older people living in the community, without severe cognitive impairment, and who were able and willing to complete the survey. Consequently, the results likely underestimate the impact of cognitive impairment or being in long-term residential resources on the distress that older people may suffer due to confinement. More research is needed to assess the impact of family functioning on the emotional state and anxiety experienced by older people with severe cognitive impairment and those living in nursing homes or other long-term care facilities Finally, the percentages of family functioning groups were very different $(N=12,90,780)$. However, they are similar to those of other studies on family functioning in the field of older people (Vera et al., 2014).

Future research should focus on studying whether improving family functioning could be an effective way to reduce anxiety an emotional problems arisen by the COVID-19 pandemic. In addition, future studies of stressful events, as confinement due to COVID-19 or other similar events could focus on how the symptoms of anxiety and depression under these situations are associated with a worsening in specific domains of family functioning, such as adaptation, 
association, growth, affection and resolution. This information can help to elucidate the pattern of decline characteristic of people with affective and anxiety problems. In addition, all of this could help in the design of family function interventions to contribute to alleviating anxiety and depression problems in elderly people in confinement situations.

An additional question that remains unresolved is whether problems with family functioning act as a risk factor to accelerate depressive and anxiety problems or if they are a consequence of these emotional problems. Future longitudinal research could more clearly distinguish between these possibilities.

Finally, to note the relevance of taking into account not only the importance of family functioning, but also the fear and avoidance of the elderly in the face of COVID-19, some professionals have difficulties in distinguishing between adaptive and pathological anxiety, perhaps because they mistakenly attribute anxiety symptoms to normal aging processes. For example, fear and avoidance are often considered normal given the aging circumstances (Wolitzky-Taylor et al., 2010). If fear and avoidance in older people are considered normal, they will not be given the importance that this study points up.

This work confirms that family dysfunction is a predisposing factor for the development of emotional problems of anxiety and depression in older people who face a potentially stressful and loss situation such as the confinement caused by COVID-19. Family dysfunction is actually a risk that is aggravated if it is associated with fear of a stressful situation (in this case the coronavirus), lack of acceptance and poor physical health.

\section{References}

Andrade, J. M., Andrade, F. C. D., de Oliveira Duarte, Y. A., \& de Andrade, F. B. (2020). Association between frailty and family functionality on health-related quality of life in older adults. Quality of Life Research, 29(6), 1665-1674. doi: 10.1007/s11136-02002433-5.

Ayalon, L. (2020). There is nothing new under the sun: Ageism and intergenerational tension in the age of the COVID-19 outbreak. International Psychogeriatrics, 32(10), 1221-1224. doi: $10.1017 / S 1041610220000575$

Bellón, J. A., Delgado, A., Luna del Castillo, J. D., \& Lardelli, P. (1996). Validez y fiabilidad del cuestionario de función familiar Apgar-familiar [Validity and reliability of the family Apgar family function test]. Atención Primaria, 18(6), 289-296.

Bergman, Y. S., Cohen-Fridel, S., Shrira, A., Bodner, E., \& Palgi, Y. (2020). COVID-19 health worries and anxiety symptoms among older adults: The moderating role of ageism. International Psychogeriatrics, 32(11), 1371-1375. doi: 10.1017/S1041610220001258

Bjelland, I., Dahl, A. A., Haug, T. T., \& Neckelmann, D. (2002). The validity of the Hospital Anxiety and Depression Scale: An updated literature review. Journal of Psychosomatic Research, 52(2), 69-77. doi: 10.1016/s0022-3999(01)00296-3

Bond, F. W., Hayes, S. C., Baer, R. A., Carpenter, K. M., Guenole, N., Orcutt, H. K., Waltz, T., \& Zettle, R. D. (2011). Preliminary psychometric properties of the Acceptance and Action Questionnaire-II: A revised measure of psychological inflexibility and 
experiential avoidance. Behavior Therapy, 42(4), 676-688. doi: 10.1016/j.beth.2011.03.007

Braam, A. W., Copeland, J. R., Delespaul, P. A., Beekman, A. T., Como, A., Dewey, M., Fichter, M., Holwerda, T. J., Lawlor B. A., Lobo, A., Magnússon, H., Prince, M. J., Reischies, F., Wilson, K. C., \& Skoog, I. (2014). Depression, subthreshold depression and comorbid anxiety symptoms in older Europeans: Results from the EURODEP concerted action. Journal of Affective Disorders, 155, 266-272. doi: 10.1016/j.jad.2013.11.011

Brooks, S. K., Webster, R. K., Smith, L. E., Woodland, L., Wessely, S., Greenberg, N., \& Rubin, G. J. (2020). The psychological impact of quarantine and how to reduce it: Rapid review of the evidence. The Lancet, 395(10227), 912-920. doi: 10.1016/S01406736(20)30460-8

Caycho-Rodríguez, T., Ventura-León, J., García-Cadena, C. H., Tomás, J. M., DomínguezVergara, J., Daniel, L., \& Arias-Gallegos, W. L. (2018). Evidencias psicométricas de una medida breve de resiliencia en adultos mayores peruanos no institucionalizados [Psychometric evidence of a brief measure of resilience in non-institutionalized Peruvian older adults]. Psychosocial Intervention, 27(2), 73-79. doi: 10.5093/pi2018a6

Chang, L., \& Krosnick, J. A. (2009). National surveys via RDD telephone interviewing versus the Internet: Comparing sample representativeness and response quality. Public Opinion Quarterly, 73(4), 641-678. doi: 10.1093/poq/nfp075

Fobair, P. A., \& Zabora, J. R. (1995). Family functioning as a resource variable in psychosocial cancer research: Issues and measures. Journal of Psychosocial Oncology, 13(1-2), $97-$ 114. doi: 10.1300/J077V13N01_06

Huppert, J. D. (2009). Anxiety disorders and depression comorbidity. In M. M. Antony, \& M. B. Stein (Eds.), Oxford library of psychology. Oxford handbook of anxiety and related disorders (pp. 576-586). Oxford: University Press.

Huremović, D. (2019). Mental health of quarantine and isolation. In Psychiatry of pandemics: A mental health response to infection outbreak (pp. 95-118). Cham: Springer.

Ibáñez-Vizoso, J. E., Alberdi-Páramo, Í., \& Díaz-Marsá, M. (2020). International mental health perspectives on the novel coronavirus SARS-CoV-2 pandemic. Revista de Psiquiatría y Salud Mental, 13(2), 111-113. doi: 10.1016/j.rpsm.2020.04.002

Itandehui, A., Pastrana, E. C., Rodríguez-Orozco, A. R., \& Gómez, C. (2009). Existe correlación entre depresión y función familiar en adultos mayores que asisten a una clínica de medicina familiar [Correlation between depression and family function in older adults from a Family Medicine Unit]. Revista Médica de Chile, 137(12), 1642 1643. doi: 10.4067/S0034-98872009001200015

Krendl, A. C., \& Perry, B. L. (2020). The impact of sheltering in place during the COVID-19 pandemic on older adults' social and mental well-being. The Journals of Gerontology Series B: Psychological Sciences and Social Sciences, 76(2), e53-e58. doi: 10.1093/geronb/gbaa110

Lazarus, R. S., \& Folkman, S. (1984). Stress, appraisal, and coping. New York, NY: Springer.

López, J., Pérez-Rojo, G., Noriega, C., Carretero, I., Velasco, C., Martínez-Huertas, J. A., López-Frutos, P., \& Galarraga, L. (2020). Psychological well-being among older adults during the COVID-19 outbreak: A comparative study of the young-old and the old-old adults. International Psychogeriatrics, 32(11), 1365-1370. doi: 10.1017/S1041610220000964

Lu, C., Yuan, L., Lin, W., Zhou, Y., \& Pan, S. (2017). Depression and resilience mediates the effect of family function on quality of life of the elderly. Archives of Gerontology and Geriatrics, 71, 34-42. doi: 10.1016/j.archger.2017.02.011 
MacLeod, S., Musich, S., Hawkins, K., Alsgaard, K., \& Wicker, E. R. (2016). The impact of resilience among older adults. Geriatric Nursing, 37(4), 266-272. doi: 10.1016/j.gerinurse.2016.02.014

Meng, H., Xu, Y., Dai, J., Zhang, Y., Liu, B., \& Yang, H. (2020). Analyze the psychological impact of COVID-19 among the elderly population in China and make corresponding suggestions. Psychiatry Research, 289, 112983. doi: 10.1016/j.psychres.2020.112983

Pierce, M., Hope, H., Ford, T., Hatch, S., Hotopf, M., John, A., Kontopantelis, E., Webb, R., Wessely, S., McManus, S., \& Abel, K. M. (2020). Mental health before and during the COVID-19 pandemic: A longitudinal probability sample survey of the UK population. The Lancet Psychiatry, 7(10), 883-892. doi: 10.1016/\$2215-0366(20)30308-4

Ruiz, F. J., Langer-Herrera, A. I., Luciano, C., Cangas, A. J., \& Beltrán, I. (2013) Midiendo la evitación experiencial y la inflexibilidad psicológica: Versión española del Cuestionario de aceptación y acción-II [Measuring experiential avoidance and psychological inflexibility: The Spanish version of the Acceptance and Action Questionnaire-II]. Psicothema, 25(1), 123-129. hdoi: 10.7334/psicothema2011.239

Smilkstein, G. (1978). The Family APGAR: A proposal for family function test and its use by physicians. The Journal of Family Practice, 6(6), 1231-1239.

Smilkstein, G. (1980). The cycle of family function: A conceptual model for family medicine. The Journal of Family Practice, 11(2), 223-232.

Sutin, A. R., Stephan, Y., Luchetti, M., \& Terracciano, A. (2018). Loneliness and risk of dementia. The Journals of Gerontology. Series B, Psychological Sciences and Social Sciences, 20, 1-9, 75(7), 1414-1422. doi: 10.1093/geronb/gby112

Terol-Cantero, C., Cabrera-Perona, V., \& Martín-Aragón, M. (2015). Revisión de estudios de la Escala de ansiedad y depresión hospitalaria (HAD) en muestras españolas [Hospital Anxiety and Depression Scale (HADS) review in Spanish samples]. Anales de Psicología, 31, 494-503. doi: 10.6018/analesps.31.2.172701

Vera, I., Lucchese, R., Munari, D. B., \& Nakatani, A. Y. K. (2014). Índex APGAR de Família na avaliação de relações familiares do idoso: Revisão integrativa [Using the family APGAR score to evaluate family relationships in the elderly: An integrative review]. Revista Eletrônica de Enfermagem, 16(1), 199-210. doi: 10.5216/ree.v16i1.22514

Verity, R., Okell, L. C., Dorigatti, I., Winskill, P., Whittaker, C., Imai, N., Cuomo-Dannenburg, G., Thompson, H., Walker, P. G. T., Fu, H., Dighe, A., Griffin, J. T., Baguelin, M., Bhatia, S., Boonyasiri, A., Cori, A., Cucunubá, Z., FitzJohn, R., Gaythorpe, K., Green, W., Hamlet, A., Hinsley, W., Laydon, D., Nedjati-Gilani, G., Riley, S., van Elsland, S., Volz, E., Wang, H., Wang, Y., Xi, X., Donnelly, C. A., Ghani, A. C., \& Ferguson, N. M. (2020). Estimates of the severity of coronavirus disease 2019: A model-based analysis. The Lancet Infectious Diseases, 20(6), 669-677. doi: 10.1016/S1473-3099(20)30243-7

Wang, C., Pan, R., Wan, X., Tan, Y., Xu, L., Ho, C. S., \& Ho, R. C. (2020). Immediate psychological responses and associated factors during the initial stage of the 2019 coronavirus disease (COVID-19) epidemic among the general population in China. International Journal of Environmental Research and Public Health, 17(5), 1729. doi: 10.3390/ijerph17051729

Wang, J., \& Zhao, X. (2012). Family functioning and social support for older patients with depression in an urban area of Shanghai, China. Archives of Gerontology and Geriatrics, 55, 574-579. doi: 10.1016/j.archger.2012.06.011

Wolitzky-Taylor, K. B., Castriotta, N., Lenze, E. J., Stanley, M. A., \& Craske, M. G. (2010). Anxiety disorders in older adults: A comprehensive review. Depression and Anxiety, 27(2), 190-211. doi: 10.1002/da.20653

Yon, Y., Mikton, C. R., Gassoumis, Z. D., \& Wilber, K. H. (2017). Elder abuse prevalence in community settings: A systematic review and meta-analysis. The Lancet Global Health, 5(2), e147-e156. doi: 10.1016/S2214-109X(17)30006-2 
Zigmond, A. S., \& Snaith, R. P. (1983). The Hospital Anxiety and Depression Scale. Acta Psychiatrica Scandinavica, 67(6), 361-370. doi: 10.1111/j.1600-0447.1983.tb09716.x

RECEIVED: June 30, 2020

ACCEPTED: October 11, 2020 